\title{
Role of the Stress-activated Protein Kinases in Endothelin-induced Cardiomyocyte Hypertrophy
}

\author{
Gabriel Choukroun, ${ }^{\ddagger}$ Roger Hajjar,, John M. Kyriakis, ${ }^{\S}$ Joseph V. Bonventre, ${ }^{\ddagger}$ Anthony Rosenzweig, ${ }^{\|}$and Thomas Force ${ }^{\star}$

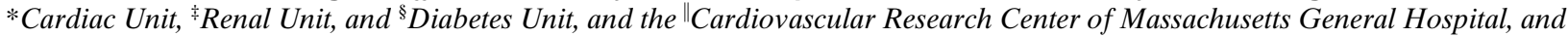 \\ Department of Medicine, Harvard Medical School, Boston, Massachusetts 02115
}

\begin{abstract}
The signal transduction pathways governing the hypertrophic response of cardiomyocytes are not well defined. Constitutive activation of the stress-activated protein kinase (SAPK) family of mitogen-activated protein (MAP) kinases or another stress-response MAP kinase, p38, by overexpression of activated mutants of various components of the pathways is sufficient to induce a hypertrophic response in cardiomyocytes, but it is not clear what role these pathways play in the response to physiologically relevant hypertrophic stimuli. To determine the role of the SAPKs in the hypertrophic response, we used adenovirus-mediated gene transfer of SAPK/ERK kinase-1 (KR) [SEK-1(KR)], a dominant inhibitory mutant of SEK-1, the immediate upstream activator of the SAPKs, to block signal transmission down the SAPK pathway in response to the potent hypertrophic agent, endothelin-1 (ET-1). SEK-1(KR) completely inhibited ET-1-induced SAPK activation without affecting activation of the other MAP kinases implicated in the hypertrophic response, p38 and extracellular signal-regulated protein kinases (ERK)-1/ERK-2. Expression of SEK-1(KR) markedly inhibited the ET-1-induced increase in protein synthesis. In contrast, the MAPK/ERK kinase inhibitor, PD98059, which blocks ERK activation, and the p38 inhibitor, SB203580, had no effect on ET-1-induced protein synthesis. ET-1 also induced a significant increase in atrial natriuretic factor mRNA expression as well as in the percentage of cells with highly organized sarcomeres, responses which were also blocked by expression of SEK-1(KR). In summary, inhibiting activation of the SAPK pathway abrogated the hypertrophic response to ET-1. These data are the first demonstration that the SAPKs are necessary for the development of agonist-induced cardiomyocyte hypertrophy, and suggest that in response to ET-1, they transduce critical signals governing the hypertrophic response. ( $J$. Clin. Invest. 1998. 102:1311-1320.) Key words: hypertrophy • endothelin • stress-activated protein kinase • c-Jun $\mathrm{NH}_{2}$-terminal kinase $\bullet$ cardiomyocyte
\end{abstract}

Address correspondence to Thomas Force, Massachusetts General Hospital East, 149-4002 13th Street, Charlestown, MA 02129-2060. Phone: 617-726-5910; FAX: 617-726-4356; E-mail: force@helix.mgh. harvard.edu

Received for publication 23 March 1998 and accepted in revised form 5 August 1998.

J. Clin. Invest.

(C) The American Society for Clinical Investigation, Inc. 0021-9738/98/10/1311/10 \$2.00

Volume 102, Number 7, October 1998, 1311-1320

http://www.jci.org

\section{Introduction}

Cardiac hypertrophy can be induced by pressure or volume overload, injury, or neurohormonal activation. In its early stages, hypertrophy is a compensatory response, but if prolonged, the heart may undergo a transition to heart failure. The signal transduction mechanisms mediating the complex response of cardiomyocytes to hypertrophic stimuli such as endothelin-1 (ET-1), ${ }^{1}$ angiotensin II, $\alpha$-adrenergic agents, or cell stretch, are poorly understood. Studies using pharmacologic inhibitors or overexpression of constitutively active components of mitogen-activated protein (MAP) kinase cascades have suggested roles for three of the kinase cascades in this response, resulting in activation of the extracellular signal-regulated kinases (ERK-1 and ERK-2), which are potently activated by growth factors and other mitogens, as well as two stress-response pathways, the stress-activated protein kinases (SAPKs) or c-Jun $\mathrm{NH}_{2}$-terminal kinases (JNKs) and the p38 family.

MAP kinase cascades consist of a three-tiered module in which a MAP kinase kinase kinase activates the downstream MAPK/ERK kinase (MEK) which, in turn, activates the MAP kinase by phosphorylating it on threonine and tyrosine residues within the catalytic domain (for reviews see references 1 and 2). When activated, the MAP kinases translocate to the nucleus where many of their primary targets, transcription factors, are located (3). These transcription factors regulate the induction of sets of genes which largely determine the ultimate biological response of the cell, including hypertrophy.

Initially, interest focused on the role of the Ras/c-Raf-1/ ERK-1/-2 pathway in the hypertrophic response. Expression of a constitutively active allele of Ras, the small GTP-binding protein in the ERK pathway, in the hearts of transgenic mice caused a phenotype resembling hypertrophic cardiomyopathy (4). In addition, expression of constitutively active Ras in cardiomyocytes in vitro was sufficient to induce genetic markers (e.g., atrial natriuretic factor [ANF] expression) and morphological changes of hypertrophy (increase in cell size and development of highly organized sarcomeres) $(5,6)$.

Although these data implicate Ras in the hypertrophic response, several studies suggest that this effect of Ras is not mediated via activation of the ERK pathway but rather the SAPK and/or p38 pathways (7-14). These studies have demonstrated

1. Abbreviations used in this paper: AdSEK, adenovirus harboring cDNA for SEK; ANF, atrial natriuretic factor; ATF-2, activating transcription factor-2; ERK, extracellular signal-regulated protein kinase; ET-1, endothelin-1; GST, glutathione $S$-transferase; MAP, mitogen-activated protein; MEK, MAPK/ERK kinase; MEKK, MAPK or ERK kinase kinase; MKK, MAP kinase kinase; SAPK, stress-activated protein kinase; SEK, SAPK/ERK kinase. 
that overexpression of constitutively active alleles of MAPK or ERK kinase kinase (MEKK-1; the MAP kinase kinase kinase upstream of the SAPKs) (9-12), MAP kinase kinase 7 (MKK7; a MEK upstream of the SAPKs) (14), or MKK3 and MKK6 (MEKs upstream of p38) $(12,13)$ induces characteristic hypertrophic responses in cardiomyocytes.

All studies to date addressing the role of the MAP kinase cascades in myocyte hypertrophy have forced constitutive activation of the MAP kinases by overexpressing activated mutants or wild-type components of these cascades. This results in supranormal and prolonged activation of normal downstream targets, and, in some cases, activation of MAP kinase cascades or other signaling pathways which are not activated under physiologic conditions (e.g., activation of the ERKs by MEKK-1), making it difficult to ascribe any effects to one specific pathway (discussed in reference 15). These caveats aside, these important studies do suggest strongly that either the SAPK or p38 pathways are sufficient to induce a hypertrophic response if they are constitutively active over prolonged periods (12-14). However, they do not clarify whether the pathways are critical to the hypertrophic response of cardiomyocytes to physiologically relevant stimuli which produce much less marked activation over much shorter periods of time.

In this study, we used SAPK/ERK kinase-1 (KR) [SEK1(KR)], a kinase-inactive mutant of SEK-1 (a MEK upstream of the SAPKs) which functions as a dominant inhibitor of SAPK activation (16). We and others have demonstrated that SEK-1(KR) effectively blocks activation of the SAPKs in response to a variety of agonists and suppresses such cellular responses as apoptosis in response to several stimuli in a number of cell types $(17,18)$. We used adenovirus-mediated gene transfer to express SEK-1(KR) in neonatal rat cardiomyocytes. This technology, by allowing us to titrate expression of SEK-1(KR), and therefore to completely inhibit agonist-induced SAPK activation without inhibiting activation of the ERKs or p38, enabled us to determine the role of the SAPK pathway in the hypertrophic response. We chose the potent hypertrophic agent, ET-1, to study the role of the MAP kinase pathways since ET-1 has been implicated in the pathophysiology of pressure overload hypertrophy and in the progression of heart failure (19-22). Our data demonstrate that the SAPKs are essential to the hypertrophic response of cardiomyocytes to ET-1.

\section{Methods}

Cell culture. Spontaneously beating neonatal myocytes were prepared from 1-2-d-old rats and cultured in F-10 medium in the presence of $5 \% \mathrm{FBS}$ and $10 \%$ horse serum as described previously (23).

Construction of recombinant adenoviral vectors carrying the SEK-1 cDNAs. SEK-1(KR), the kinase-inactive mutant of SEK-1, was produced by PCR using primers designed to produce a Lys-to-Arg substitution at Lys 129 in the ATP-binding site of SEK-1 as described in (16). For SEK-1(ED), the constitutively active mutant of SEK-1, the primers created Ser-to-Glu and Thr-to-Asp substitutions at Ser 220 and Thr 224, respectively, the sites of regulatory phosphorylation of SEK-1. Both of these constructs, carrying the 9-amino acid M2 FLAG epitope at their $\mathrm{NH}_{2}$ termini, were subcloned into the Not1 and Xho1 sites of the shuttle vector, pAdRSV4. Both constructs were sequenced. AdSEK-1(KR) and AdSEK-1(ED), the recombinant adenoviruses, were prepared by cotransfection with pJM17 as described (23, 24). Plaque-purified recombinant virus was propagated in 293 cells and high titer stocks were purified by $\mathrm{CsCl}$ density gradient centrifugation. The viral stocks were determined to have titers of $2 \times$
$10^{10} \mathrm{pfu} / \mathrm{ml}$ for AdSEK-1(KR) and $10^{10} \mathrm{pfu} / \mathrm{ml}$ for AdSEK-1(ED) by plaque assay in 293 cells. Particle to pfu ratio was 55:1 and 90:1 for AdSEK-1(KR) and AdSEK-1(ED), respectively. The recombinant adenovirus carrying the Escherichia coli LacZ gene encoding $\beta$-galactosidase (AdLacZ) was kindly provided by Dr. David Dichek (Gladstone Institute for Cardiovascular Diseases, San Francisco, CA).

Immunoblot analysis. For Western blot analysis, cell lysates were matched for protein concentration and then separated by SDSPAGE and transferred to a polyvinylidene difluoride membrane (Bio-Rad Laboratories, Richmond, CA). The membranes were blocked in 5\% nonfat milk and then incubated with the indicated antibodies for $1 \mathrm{~h}$ at room temperature. Antibody binding was detected with a peroxidase-conjugated goat anti-rabbit or anti-mouse IgG and chemiluminescence.

Immune complex kinase assays. Immune complex kinase assays for endogenous MAP kinase activity were performed as described $(25,26)$. In brief, cell lysates were matched for protein concentration and then were incubated with anti-SAPK antibody (27), anti-ERK-1 and -2 , or anti-p38 antibodies (Santa Cruz Biotechnology, Santa Cruz, CA) with protein G-Sepharose beads for $3 \mathrm{~h}$. Beads were washed nine times and then were incubated for $20 \mathrm{~min}$ at $30^{\circ} \mathrm{C}$ with glutathione $S$-transferase (GST)-c-Jun(1-135) (SAPK assay), myelin basic protein (MBP; ERK assay), or GST-activating transcription factor-2(8-94) [GST-ATF-2(8-94)] (p38 assay) and $100 \mu \mathrm{M}\left[\gamma^{-32} \mathrm{P}\right] \mathrm{ATP}$ $(3,000-5,000 \mathrm{cpm} / \mathrm{pmol})$ in the presence of $10 \mathrm{mM} \mathrm{MgCl}$. The reactions were stopped with SDS sample buffer and proteins were separated by SDS-PAGE. After autoradiography, the GST-c-Jun, MBP, or GST-ATF-2 bands were excised from the dried gels and the radioactivity incorporated was determined by scintillation counting. Data are presented as milliunits of activity where $1 \mathrm{mU}$ of activity transfers

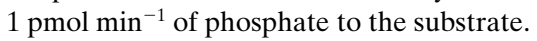

RNA extraction and Northern blot analysis. Total RNA was prepared using the single-step acid guanidine thiocyanate-phenol chloroform extraction method as described previously (28). Total RNA (10 $\mu \mathrm{g} /$ lane) was separated in a $1.2 \%$ formaldehyde agarose gel and transferred to a nylon membrane. The blot was hybridized using $\left[\alpha-{ }^{32} \mathrm{P}\right] \mathrm{dCTP}$ random prime-labeled rat ANF and $\beta$-actin cDNA probes (kindly provided by Dr. Ken Bloch, Massachusetts General Hospital, Boston, MA).

Protein synthesis measurements. $24 \mathrm{~h}$ after infection with either AdLacZ, AdSEK-1(KR), or AdSEK-1(ED), cardiocytes were made quiescent by incubation in F-10 medium containing $0.1 \%$ FCS for 24 h. For determination of leucine incorporation, cells in triplicate wells of 12-well plates were stimulated with ET-1 (100 nM; Sigma Chemical Co., St. Louis, MO) for $24 \mathrm{~h}$ in serum-free F-10 medium and then incubated in the same medium with $1.0 \mu \mathrm{Ci} / \mathrm{ml}\left[{ }^{3} \mathrm{H}\right] l$ leucine for an additional $6 \mathrm{~h}$. The medium was aspirated and the cells were washed with ice-cold PBS and fixed on ice for 30 min with cold $10 \%$ TCA. After washing twice with 5\% TCA, and once with water, the radioactivity incorporated into the TCA-precipitable material was determined by liquid scintillation counting after solubilization in $0.25 \mathrm{M} \mathrm{NaOH}$.

For determination of total protein, $24 \mathrm{~h}$ after infection, cells were incubated in serum-free F-10 media for $24 \mathrm{~h}$, and then exposed to ET-1 $(100 \mathrm{nM})$ for $48 \mathrm{~h}$ in serum free F-10 media. Protein concentration was determined using a modification of the Lowry technique (29). DNA concentration was determined after extraction by spectrophotometric analysis.

Determination of sarcomere organization. Cardiomyocytes grown on glass coverslips were infected with AdLacZ, AdSEK-1(KR), AdSEK-1(ED), or with no virus. $24 \mathrm{~h}$ later, they were exposed to ET-1 in serum-free medium for $48 \mathrm{~h}$. The cells were then fixed for $20 \mathrm{~min}$ with $4 \%$ paraformaldehyde $/ 5 \%$ sucrose in PBS, permeabilized with $0.1 \%$ Triton $\mathrm{X}-100$ for $5 \mathrm{~min}$, blocked for $10 \mathrm{~min}$ with $1 \% \mathrm{BSA}$, and then stained for F-actin with FITC-conjugated phalloidin (Molecular Probes, Inc., Eugene, OR). At least 300 cells per coverslip were scored for the presence of highly organized sarcomeres. Cells were photographed using a Nikon FXA photomicroscope.

Statistical analysis. Data are expressed and presented in the figures as mean \pm SEM or SD where appropriate. A Student's $t$ test was used 
to compare the means of normally distributed continuous variables. A value of $P<0.05$ was chosen as the limit of statistical significance.

\section{Results}

\section{Profile of MAP kinase activation by ET-1 in cardiomyocytes}

To dissect the signaling pathways regulating ET-1-induced cardiomyocyte hypertrophy, we first determined the pattern of activation of the various MAP kinases in response to ET-1 $(100 \mathrm{nM})$. As expected, the ERKs were significantly activated by ET-1 (ninefold at $20 \mathrm{~min}$ of stimulation; see below, Fig. 3 $B)$. The SAPKs were activated up to sixfold at 20 min after ET-1, and two- to threefold activation persisted for $60 \mathrm{~min}$ (Fig. 1$)$. In contrast, p38 was minimally activated $(<1.2$-fold at all time points) (Fig. 1).

\section{Gene transfer of SEK-1(KR) and SEK-1(ED)} in cardiomyocytes

To explore the role of the SAPK pathway in ET-1-induced myocyte hypertrophy, we used adenovirus-mediated gene transfer of M2 epitope-tagged SEK-1(KR) to block activation of the SAPKs and M2 epitope-tagged SEK-1(ED) to examine the effect of constitutive activation of the SAPK pathway. Western blotting of cell lysates revealed high levels of expression of the two constructs (Fig. 2). Staining of myocytes with anti-M2 antibody revealed expression of the kinases in $>90 \%$
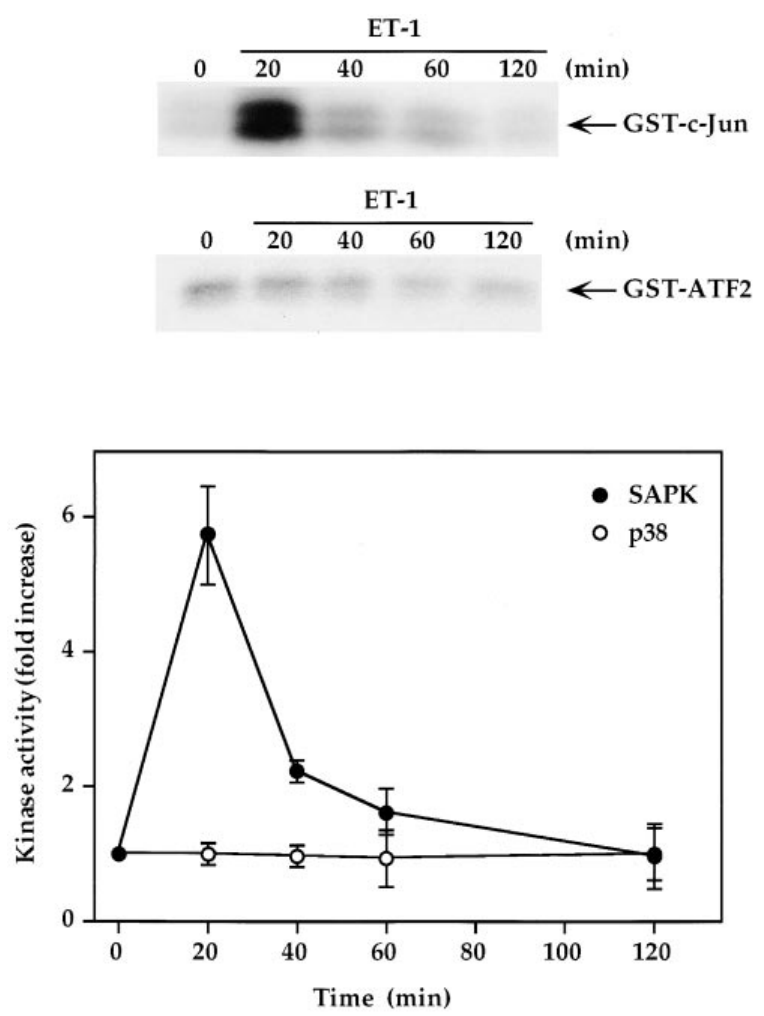

Figure 1. Time course of activation of stress-response protein kinases by ET-1 in neonatal rat cardiomyocytes. Neonatal rat cardiomyocytes were exposed to ET-1 (100 nM) for 0, 20, 40, 60, or $120 \mathrm{~min}$. Cell lysates were subjected to immunoprecipitation with anti-SAPK or antip38 antibodies before assay with GST-c-Jun(1-134) or GST-ATF-2 (8-94) for the SAPKs and p38, respectively. Representative autoradiograms of kinase assays are shown above the graphs of kinase activity.

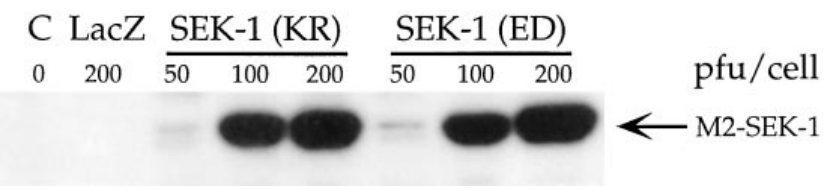

Figure 2. Adenovirus-mediated gene transfer of M2 flag-tagged SEK-1(KR) and SEK-1(ED) in rat neonatal cardiomyocytes. Neonatal rat cardiomyocytes were infected with adenoviruses encoding LacZ at an moi of $200 \mathrm{pfu} / \mathrm{cell}$, or M2-SEK-1(KR) or M2-SEK-1(ED) at an moi of 50,100, or $200 \mathrm{pfu} / \mathrm{cell}$. $48 \mathrm{~h}$ after infection, the cells were lysed and $25 \mu \mathrm{g}$ of each lysate was subjected to Western blotting with anti-M2 monoclonal antibody (Kodak Scientific, Rochester, NY). Extract from uninfected cardiomyocytes $(C)$ was also run on the gel.

of cells at an moi of 100 pfu/cell (data not shown). This moi was used in all subsequent experiments.

$S E K-1(K R)$ functions as a dominant inhibitor of $S A P K a c-$ tivation by ET-1. Adenoviral gene transfer of SEK-1(KR) proved to be a potent yet specific means of inhibiting ET-1induced SAPK activation (Fig. $3 A$ ). Expression of SEK-1(KR) abrogated ET-1-induced activation of the SAPKs (Fig. $3 A$ ), but had no effect on ET-1-induced ERK activation (Fig. $3 B$ ) or on the minimal ET-1-induced activation of p38 (Fig. $3 \mathrm{C}$ ). Abrogation of ET-1-induced SAPK activation was not due to adenoviral infection alone since infection of cells with a virus encoding $\beta$-galactosidase (AdLacZ) had no effect on ET-1stimulated SAPK activity (Fig. $3 A$ ). These data confirm that adenoviral-mediated gene transfer of SEK-1(KR) blocks SAPK signaling, allowing us to study the role of the pathway in the hypertrophic response. We also found no significant activation of the ERKs or p38 at 24 or $48 \mathrm{~h}$ after infection with adenovirus harboring LacZ, suggesting that adenovirus-induced activation of the ERKs (30), if present in cardiocytes, is very transient and should not have interfered with our studies.

Expression of SEK-1(ED) activates the SAPKs. Infection of myocytes with the adenovirus harboring SEK-1(ED) induced sustained expression of the kinase (Fig. 2) which was clearly active based on its ability to activate bacterially expressed SAPK in vitro (data not shown). However, $72 \mathrm{~h}$ after infection of myocytes with AdSEK-1(ED), SAPK activity was not significantly increased over activity in uninfected, vehicle-treated cells (Fig. 3 A). SAPK activity was modestly increased at earlier time points, however. At $30 \mathrm{~h}$ after infection with AdSEK1(ED), SAPK activity was 1.5 -fold increased compared with AdLacZ-infected cells ( $P<0.01$; Fig. 4). This compares to 3.3and 1.5-fold activation of the SAPKs in uninfected cells exposed to ET-1 for 20 or 120 min, respectively (Fig. 4).

These data suggest that persistent activation of the SAPKs by SEK-1(ED) leads to the induction of counterregulatory mechanisms which inactivate the SAPKs. This could be due to increased expression of various phosphatases (31) or inhibitory proteins (e.g., JIP [32]), or to other undefined mechanisms, and has also been seen in cell lines expressing constitutively active MEK-1 (33). Despite this, our data suggest that we could use AdSEK-1(ED) to study the effects of constitutive, low-grade activation of the SAPKs on the expression of various components of the hypertrophic phenotype.

\section{Inhibition of the p38 and ERK pathways}

To explore the role of the p38 pathway and the ERKs in the hypertrophic response, we used pharmacologic inhibitors of 
A
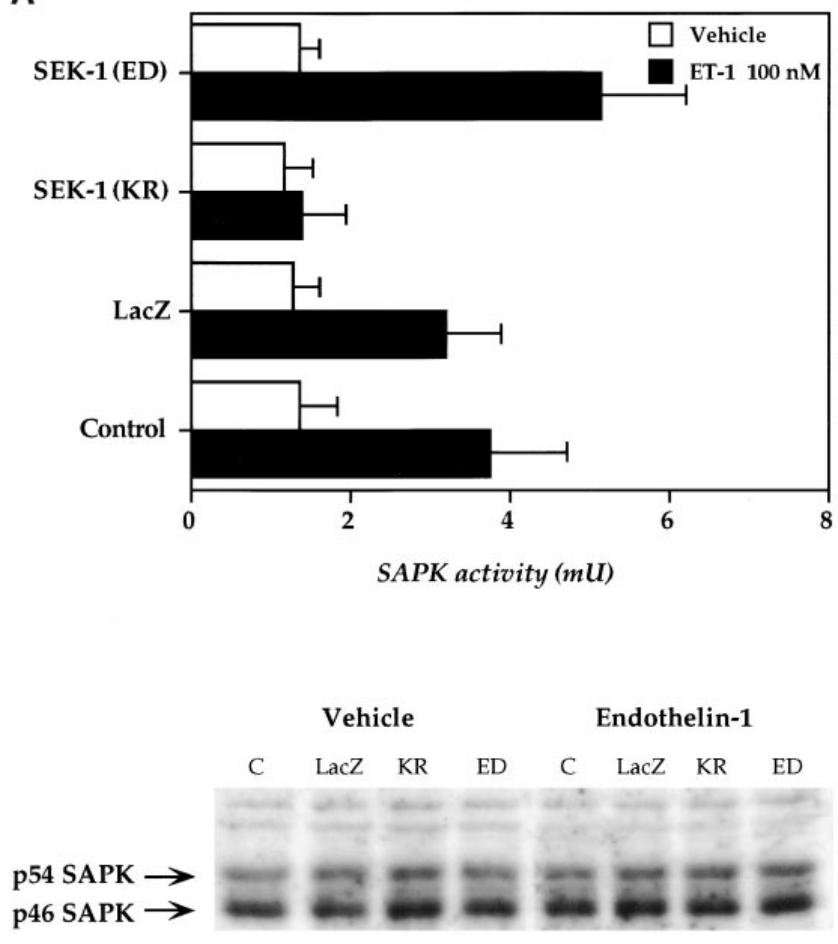

C
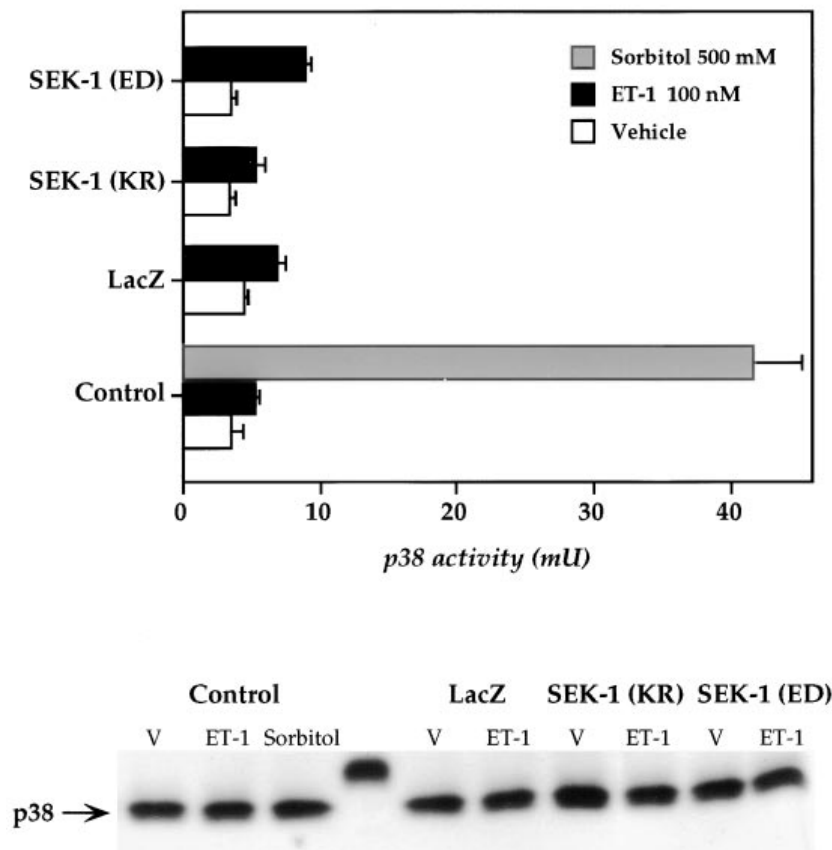

these pathways. SB203580 is a potent inhibitor of p38 $\alpha$ and p38 $3\left(\mathrm{IC}_{50}\right.$ of $\left.0.3-0.6 \mu \mathrm{M}\right)$, but not of two other p38 family members, p38y (SAPK3) and SAPK4 (34). The drug does not inhibit the ERKs, but it does inhibit several SAPK isoforms in vitro at concentrations $\geq 10 \mu \mathrm{M}$ (35). Therefore, we used SB203580 at a concentration of $5 \mu \mathrm{M}$ to inhibit p38 in situ. This concentration did not inhibit SAPK activation but inhibited sorbitol-induced activation of the p38 target, MAPKAP kinase- 2 by $80 \%$ (data not shown). We could not determine the percent inhibition of ET-1-induced p38 activation since
B
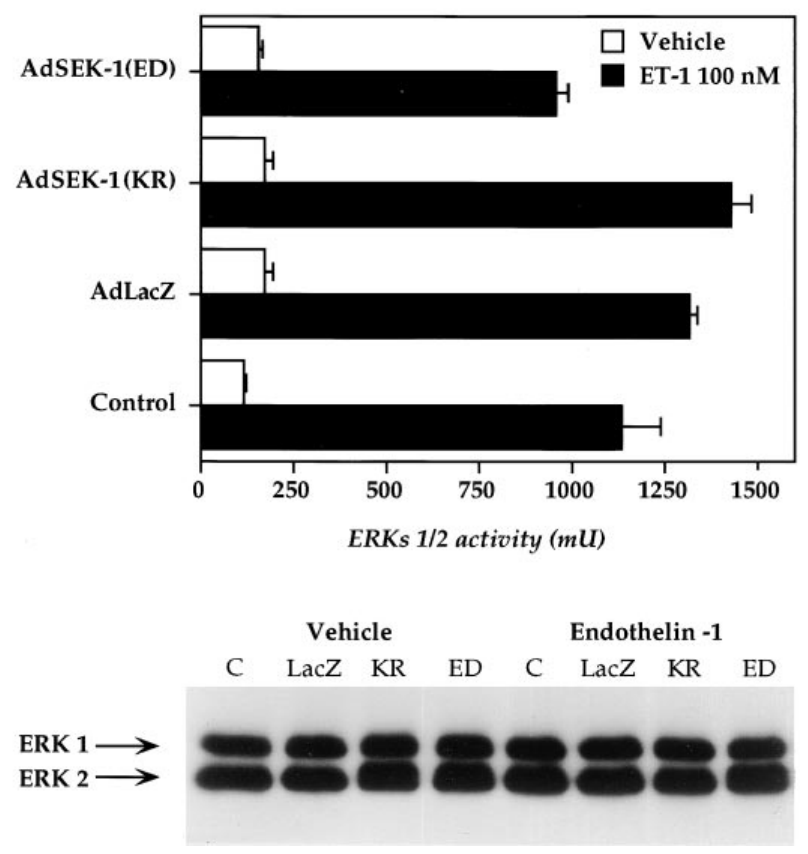

Figure 3. Adenovirus-mediated gene transfer of SEK-1(KR) specifically inhibits ET-1-induced SAPK activation. $(A)$ Activation of the SAPKs. Uninfected (Control) myocytes or myocytes infected with AdLacZ, AdSEK-1(KR), or AdSEK-1(ED) were exposed to vehicle or ET-1 (100 nM). After 20 min, cell lysates were prepared and immune complex kinase assay for the SAPKs was performed using GSTc-Jun(1-135) as substrate. Western blot below the graph demonstrates equivalent expression of the p54 and p46 SAPKs in each of the conditions. (B) Activation of ERK-1/-2. Uninfected (Control) myocytes or myocytes infected with AdLacZ, AdSEK-1(KR), or AdSEK-1(ED) at an moi of $100 \mathrm{pfu} / \mathrm{cell}$ were exposed to vehicle or ET-1 (100 nM). After $20 \mathrm{~min}$, cell lysates were prepared and immune complex kinase assay for ERKs was performed using myelin basic protein as substrate. Western blot demonstrating equivalent expression of ERK-1 and ERK-2 in the various conditions is below the graph. $(C)$ Activation of p38. Cells infected with AdLacZ, AdSEK-1(KR), or AdSEK-1(ED) or uninfected cells (Control) were exposed to vehicle, ET-1 (100 nM for 20 $\mathrm{min}$ ), or, as a positive control, sorbitol (500 $\mathrm{mM}$ for $30 \mathrm{~min}$ ). After immunoprecipitation with anti-p38 $\alpha$ antibody, immune complex kinase assays were performed using GST-ATF-2(8-94) as substrate. Western blot below the graph confirms equivalent amounts of $\mathrm{p} 38$ in the various conditions. The band in the fourth lane is a prestained molecular weight marker which reacts nonspecifically with the secondary antibody. For all figures, the data are presented as the mean \pm SD for duplicate assays.

ET-1 did not increase MAPKAP kinase-2 activity, presumably because $\mathrm{p} 38$ activation by ET-1 was minimal.

PD98059 inhibits MEK-1, the immediate upstream activator of the ERKs, at concentrations in the range of $5 \mu \mathrm{M}$ in situ. In our experiments, PD98059, at a concentration of $25 \mu \mathrm{M}$, inhibited ET-1-induced activation of ERK-1 and ERK-2, but only by $\sim 60 \%$. These data suggest that ET-1-induced activation of the ERKs in cardiomyocytes proceeds, at least in part, via MEK-2, which is fully inhibited by PD98059 only at concentrations in the range of $50 \mu \mathrm{M}$. Therefore, $50 \mu \mathrm{M}$ PD98059, 


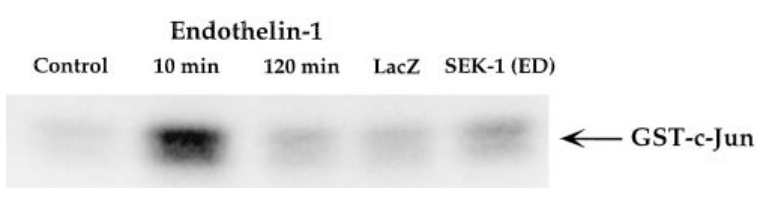

Figure 4. Activation of the SAPKs by SEK-1(ED). SAPK activity was determined in uninfected cardiomyocytes exposed to vehicle or ET-1 for 10 or $120 \mathrm{~min}$, or in myocytes infected with AdSEK-1(ED) or AdLacZ. Immune complex kinase assays of endogenous SAPKs were performed $30 \mathrm{~h}$ after infection. Autoradiogram is from an experiment representative of $n=3$.

which completely inhibited ET-1-induced ERK activation (data not shown), was used in all subsequent experiments.

\section{MAP kinase pathways mediating the hypertrophic response in myocytes}

We examined the effect of expressing the dominant inhibitory mutant of SEK-1, SEK-1(KR), on the ET-1-induced hypertrophic response in cardiomyocytes. Cells in culture stimulated with ET-1 undergo several phenotypic changes characteristic of the hypertrophic response. These include enhanced protein syn- thesis and increases in cell size, enhanced sarcomere organization, and the induction of several genes including those for several sarcomeric proteins ( $\beta$-myosin heavy chain, $\alpha$-skeletal actin, and myosin light chain-2) and for atrial natriuretic proteins.

Protein synthesis. We examined protein synthesis since it is central to the hypertrophic response. We found that ET-1 induced a marked increase in $\left[{ }^{3} \mathrm{H}\right]$ leucine incorporation (Fig. 5 $A$, left). In cells infected with recombinant adenovirus encoding the dominant inhibitory mutant of SEK-1, SEK-1(KR), the ET-1-induced increase in $\left[{ }^{3} \mathrm{H}\right]$ leucine incorporation was completely inhibited. This effect was not due to infection with the virus alone since infection with AdLacZ did not block ET-1induced $\left[{ }^{3} \mathrm{H}\right]$ leucine incorporation. We confirmed that the increase in $\left[{ }^{3} \mathrm{H}\right]$ leucine incorporation was due to enhanced protein synthesis and not enhanced protein turnover by measuring the ET-1-induced increase in protein concentration and normalizing it for the amount of DNA (Fig. 5 A, right). ET-1 induced a marked increase in protein synthesis in uninfected cells and in cells infected with AdLacZ or AdSEK-1(ED), but not in cells infected with AdSEK-1(KR). These data suggest that a functional SAPK pathway is necessary for the enhanced protein synthesis characteristic of the hypertrophic response to ET-1.
A

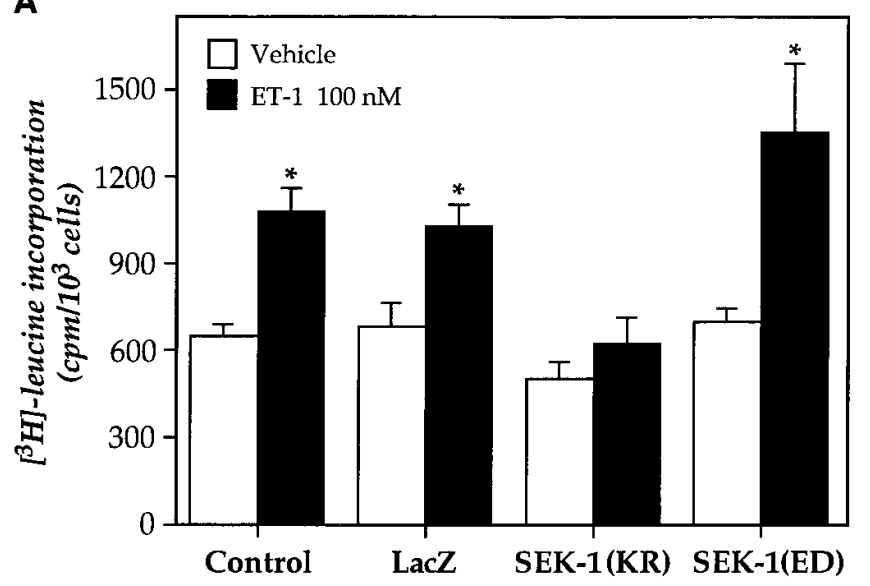

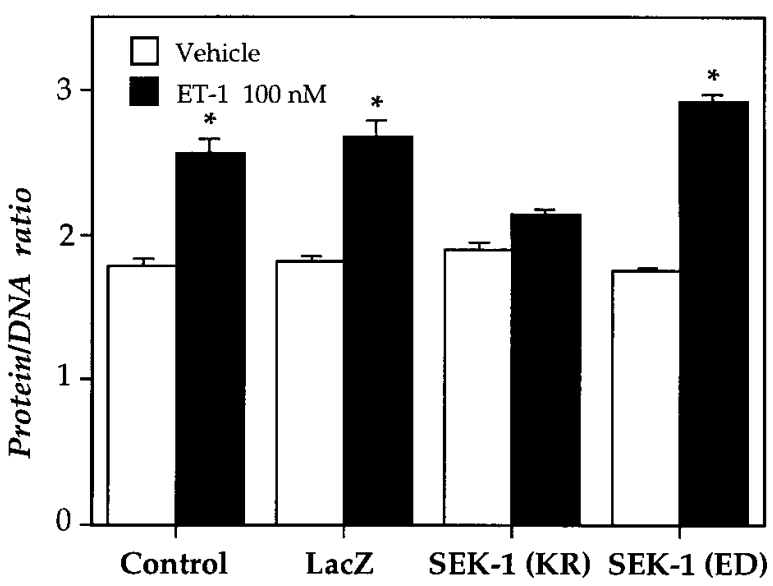

B

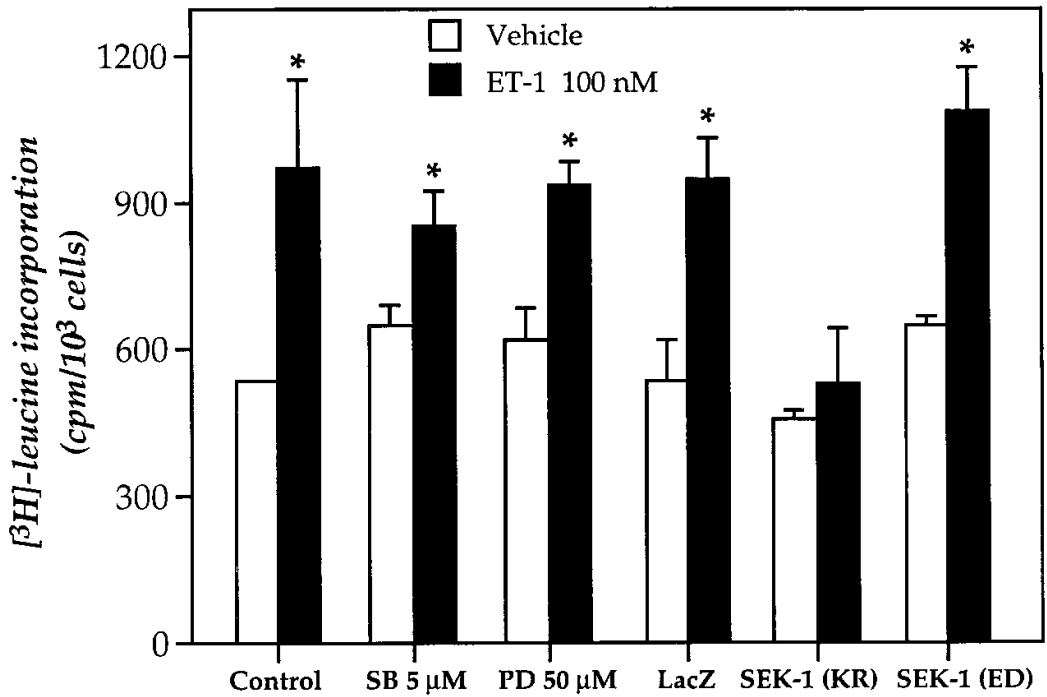

Figure 5. SEK-1(KR), but not PD98059 or SB203580, blocks ET-1-induced protein synthesis. (A) Uninfected neonatal cardiomyocytes (Control) or myocytes infected at an moi of $100 \mathrm{pfu} / \mathrm{cell}$ with AdLacZ, AdSEK-1(KR), or AdSEK-1(ED) for $24 \mathrm{~h}$ were incubated with ET-1 $(100 \mathrm{nM})$ or vehicle for $30 \mathrm{~h} \mathrm{(left)}$ or $48 \mathrm{~h}$ (right) in serum-free media. $\left[{ }^{3} \mathrm{H}\right]$ Leucine was added for the final $6 \mathrm{~h}($ left $)$. $\left[{ }^{3} \mathrm{H}\right]$ Leucine incorporation $(l e f t)$ and total protein concentration controlled for DNA concentration $($ right $)$ were determined as described in Methods. $* P<0.001$ for ET-1 vs. vehicle. (B) Uninfected cardiomyocytes were preincubated with vehicle, SB203580 $(5 \mu \mathrm{M})$, or PD98059 $(50 \mu \mathrm{M})$ for $60 \mathrm{~min}$ and then incubated with ET-1 or vehicle for $48 \mathrm{~h}$ in serum-free media. Other myocytes were infected with AdLacZ, AdSEK-1(KR), or AdSEK-1(ED) for $24 \mathrm{~h}$ followed by ET-1 for $48 \mathrm{~h}$. $\left[{ }^{3} \mathrm{H}\right]$ Leucine incorporation was determined as described in Methods. $* P<$ 0.001 for ET-1 vs. vehicle. 
We next explored the role of the ERKs and p38 in ET1-induced protein synthesis. We determined ET-1-induced $\left[{ }^{3} \mathrm{H}\right]$ leucine incorporation after pretreatment of cells with 50 $\mu \mathrm{M}$ PD98059. PD98059 did not prevent the ET-1-induced increase in $\left[{ }^{3} \mathrm{H}\right]$ leucine incorporation in cells (Fig. $5 \mathrm{~B}$ ), suggesting a functional ERK pathway is not necessary for enhanced protein synthesis in cardiomyocytes exposed to ET-1. We next explored the effect of $5 \mu \mathrm{M}$ SB203580 on ET-1-induced $\left[{ }^{3} \mathrm{H}\right]$ leucine incorporation. In the presence of SB203580, ET-1 significantly increased $\left[{ }^{3} \mathrm{H}\right]$ leucine incorporation (Fig. $5 \mathrm{~B}$ ). These data, taken together, strongly suggest that activation of the SAPK pathway is critical to the increase in protein synthesis in cardiomyocytes exposed to ET-1. The ERK pathway appears to play no role in ET-1-induced protein synthesis. While we cannot rule out a role for the p38 family members which are not inhibited by SB203580, it is clear that activation of p38s by ET-1 in the absence of SAPK activation is not sufficient to induce protein synthesis in cardiomyocytes.

We next attempted to determine whether activation of the SAPK pathway alone, in the absence of ERK-1/-2 and p38 activation, was sufficient to enhance protein synthesis. To address this question, we used adenoviral gene transfer to express constitutively active SEK-1(ED) in cardiomyocytes. In contrast to studies using overexpression of MKK7 which resulted in a fourfold increase in SAPK activity and significant increases in cell size (14), expression of SEK-1(ED) in the absence of ET-1 produced only a small and statistically insignificant increase in protein synthesis in cardiomyocytes (Fig. 5, A and $B$ ). However, expression of SEK-1(ED) did amplify the ET-1-induced increase in protein synthesis significantly $[P<$ 0.05 for AdSEK-1(ED) vs. AdLacZ; Fig. 5 A]. These data suggest that the modest (1.5-fold) activation of the SAPKs observed after infection of myocytes with AdSEK-1(ED) was not sufficient, by itself, to increase total protein synthesis but did enhance the response to ET-1, consistent with its amplification of the ET-1-induced increase in SAPK activity (Fig. $3 A$ ).

Gene expression. We also examined the role of the SAPK pathway in modulating the induction of ANF in response to ET-1. ET-1 induced a significant increase in ANF mRNA, and this increase was completely inhibited by adenovirus-mediated gene transfer of SEK-1(KR) but not by infection of cells with AdLacZ (Fig. 6). These data confirm that the SAPKs are necessary for the expression of a second marker of the hypertrophic phenotype in cardiomyocytes, ANF induction.

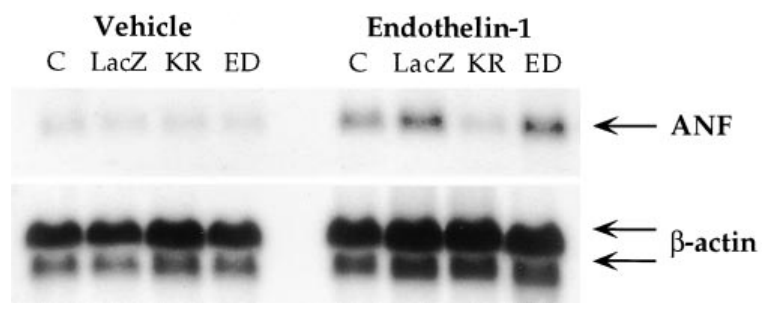

Figure 6. SEK-1(KR) blocks induction of ANF mRNA by ET-1. Uninfected myocytes $(C)$ or myocytes infected with AdLacZ, AdSEK1(KR), or AdSEK-1(ED) at an moi of $100 \mathrm{pfu} / \mathrm{cell}$ for $24 \mathrm{~h}$ were exposed to vehicle (left) or ET-1 (right) for $48 \mathrm{~h}$ in serum-free media and Northern blot analysis for ANF expression was performed (top). The blot was also probed for $\beta$-actin expression which confirmed equivalent loading of RNA (bottom).
Sarcomere organization. The third phenotypic change characteristic of the hypertrophic response that we examined was the development of highly organized sarcomeres in cardiomyocytes. Cells were stained with FITC-conjugated phalloidin which stains F-actin. ET-1 induced a marked increase in the percentage of cells with highly organized sarcomeres (Fig. 7, $A$ and $B$ ). Infection of cells with AdLacZ had no effect on the percentage of control or ET-1-stimulated cells with organized sarcomeres, suggesting adenoviral infection alone had no effect on this marker. Infection of cells with AdSEK-1(KR) blocked the ET-1-induced increase in sarcomere organization, suggesting the SAPKs are also necessary for the expression of this component of the hypertrophic response. Infection of cells with AdSEK-1(ED) significantly increased the percentage of cells with organized sarcomeres. These data suggest that the modest activation of the SAPKs seen in cells infected with AdSEK-1(ED), while not sufficient to increase total protein synthesis, was sufficient to induce sarcomere organization (Fig. 7, $A$ and $B$ ).

\section{Discussion}

Several stimuli appear to be involved with the development of cardiomyocyte hypertrophy. Initially, cellular stretch, due to increased afterload or preload, appears to trigger many of the components of the hypertrophic response (36). In addition, peptide growth factors (e.g., FGF and PDGF), TGF- $\beta$, and some cytokines (cardiotrophin-1 and leukemia inhibitory factor) can cause myocyte hypertrophy in vitro $(37,38)$. Neurohormonal agents also likely play a critical role $(21,39)$. These agents, which include angiotensin II, ET-1, and $\alpha$-adrenergic agents, not only increase afterload, enhancing cell stretch, but also, via interactions with serpentine receptors coupled to heterotrimeric $\mathrm{G}$ proteins of the $\mathrm{Gq}$ family, directly activate the hypertrophic response of myocytes independent of their effects on afterload (39-41). Recently, studies which blocked signaling from Gq-linked receptors by overexpressing the $\mathrm{COOH}$-terminal tail of the $\alpha \mathrm{q}$ subunit in transgenic mice suggested that signaling from Gq-linked receptors may play a critical role in pressure overload hypertrophy in vivo (42). Given the diverse array of stimuli which induce an hypertrophic response, it seemed unlikely, until recently, that any "final common" cytosolic signaling pathway(s) would be identified which controlled induction of the hypertrophic response. Since the initial cloning and characterization of the SAPK and p38 subfamilies of MAP kinases $(27,43,44)$, it has become apparent that many of the stimuli which induce myocyte hypertrophy, including agonists with Gq-coupled receptors, activate the SAPKs and, in some cases, p38 (10, 11, 41, 45-48). Furthermore, two signaling molecules clearly implicated in the hypertrophic response based on studies with transgenic animals, $\alpha \mathrm{q}$ and Ras, also activate the SAPKs $(43,49)$.

Most hypertrophic stimuli also activate the ERK cascade, but several studies using either the MEK-1 inhibitor, PD98059, a constitutively active mutant of MEK-1, or dominant inhibitory mutants of c-Raf- 1 and the ERKs, have suggested that the ERKs are neither necessary nor sufficient for expression of several components of the hypertrophic response $(7,8,10,50)$. Consistent with these prior studies, we found that the ERKs were markedly activated by ET-1 in cardiomyocytes, but despite the marked activation, inhibition of ERK activation with 
Vehicle

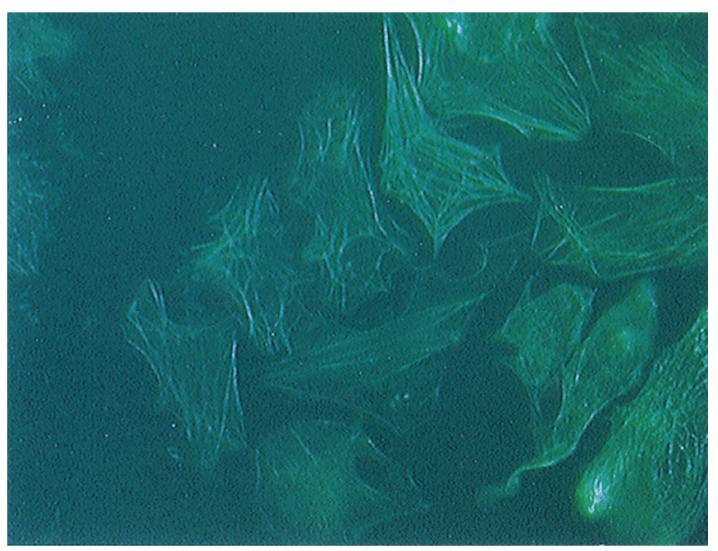

\section{Control}

SEK-1 (KR)
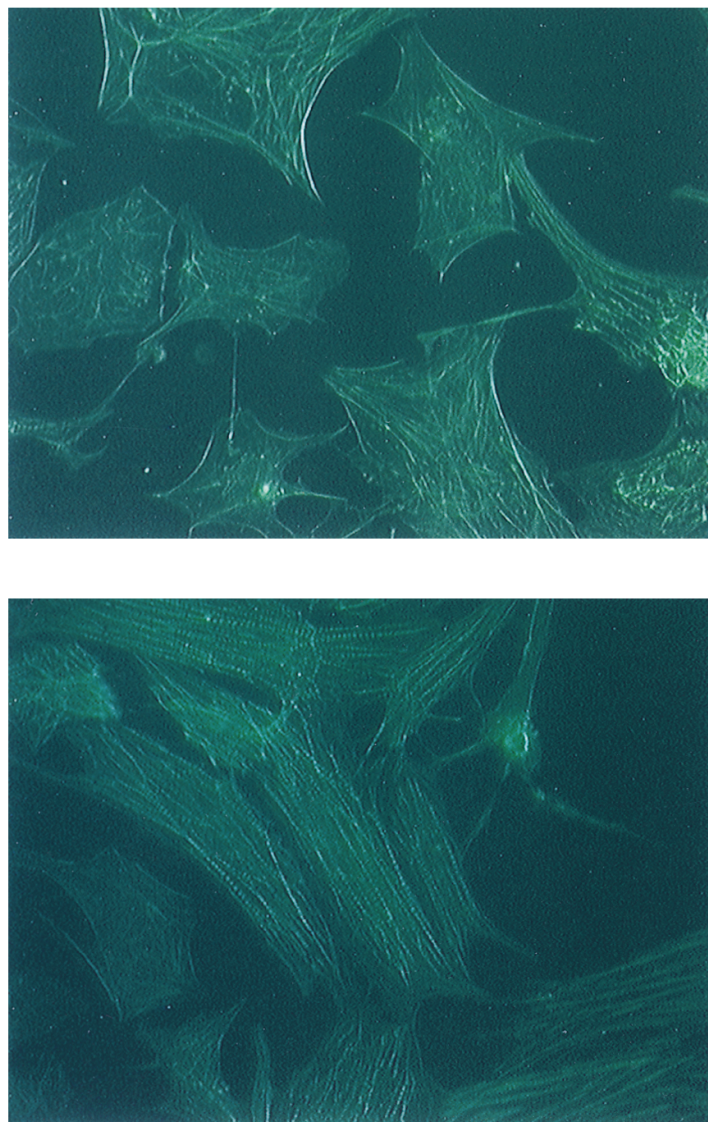

Endothelin-1
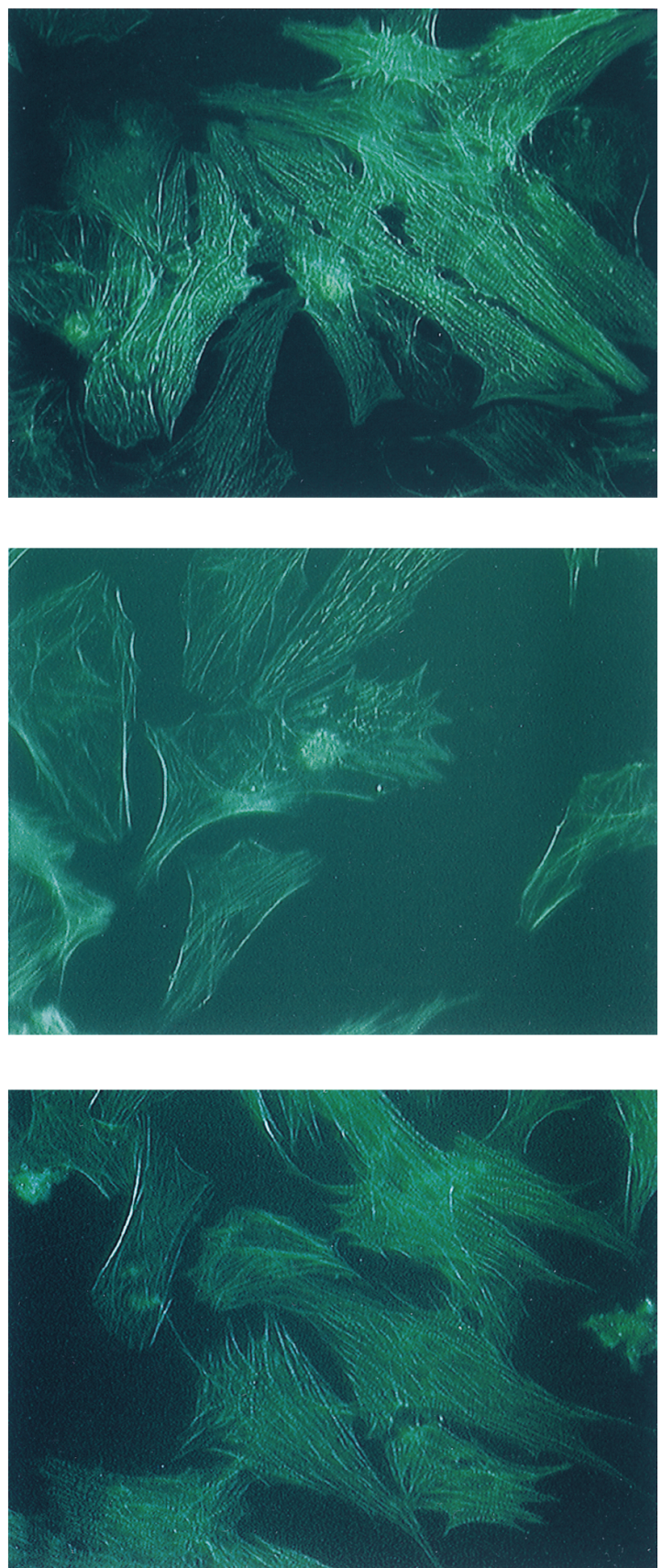

Figure 7. SEK-1(KR) blocks sarcomere organization in response to ET-1. (A) Uninfected cardiomyocytes (Control) or myocytes infected with AdSEK-1(KR) or AdSEK-1(ED) were exposed to vehicle (left) or ET-1 (100 nM; right) for $48 \mathrm{~h}$ before staining with FITC-conjugated phalloidin. In vehicle-treated cells (left), a larger number of the SEK-1(ED)-expressing cells had highly organized sarcomeres compared with control or SEK-1(KR)-expressing cells. ET-1 increased the percentage of cells with highly organized sarcomeres in control and SEK-1(ED)-expressing myocytes, but not in SEK-1(KR)-expressing cells. $(B)$ The effect of SEK-1(KR) and SEK-1(ED) on ET-1-induced sarcomere organization. At least 300 cells per condition were scored for the presence of highly organized sarcomeres. Data are expressed as the percentage of cells with organized sarcomeres in the various conditions.

PD98059 had no effect on ET-1-induced protein synthesis (Fig. 5) or sarcomere organization (data not shown). These data confirm that the ERKs are not necessary for expression of these two components of the hypertrophic phenotype.

Several recent studies have suggested a role for the stressresponse MAP kinases in the hypertrophic response. Two studies have demonstrated that constitutive activation of p38s induced by expression of activated mutants of MKK6 or MKK3, the immediate upstream activators of the p38s, increased cell size, enhanced ANF expression, and enhanced sarcomeric organization $(12,13)$. More recently, overexpression of wild-type or constitutively active MKK7 (a MEK 


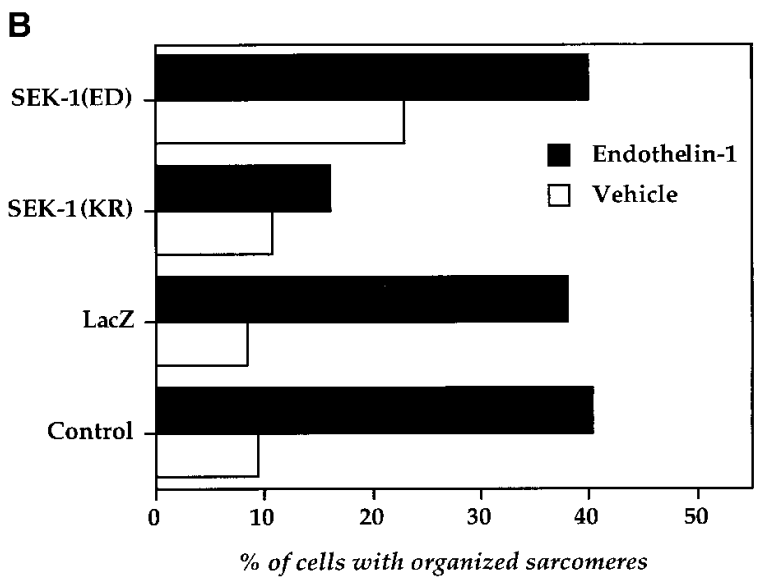

Figure 7 (Continued)

which, like SEK-1, is upstream of the SAPKs) also increased cell size, and enhanced ANF expression and sarcomere organization (14). Overexpression of these MKK3 and MKK6 constructs produced persistent 3-12-fold activation of p38s, and expression of the MKK7 constructs produced persistent 4-fold activation of the SAPKs $(13,14)$. These profiles of activation bear little relationship to the transient activation that occurs in response to most hypertrophic stimuli. For example, SAPK activity in cardiomyocytes after cell stretch or ET-1 returns to control levels by $2 \mathrm{~h}$ (Fig. 1 and references 46 and 47). Such marked differences in the duration of MAP kinase activation could have profoundly different effects on the biological response of the cell. For example, growth factors can cause cells to either proliferate or to exit the cell cycle and undergo differentiation depending on whether ERK activation is transient or sustained (for review see reference 51). Thus, the studies of Chien and co-workers $(13,14)$, which used constitutively active mutants to activate the SAPKs and p38s, confirmed that sustained activation of either of the pathways is sufficient to induce a hypertrophic response, but it remains unclear whether the pathways are necessary and what role they play in the hypertrophic response to physiologically relevant stimuli.

We used a dominant inhibitory mutant of SEK-1 to dissect the role of the SAPK cascade in the hypertrophic response. We chose this approach since at the present time there are no adequate pharmacologic inhibitors of the SAPK pathway. Our approach takes advantage of the relative specificity of MEKs for MAP kinases. That is, at the level of the MEKs there is relatively little crosstalk between the various MAP kinase pathways. Similar selectivity exists for the kinase-inactive mutant of SEK-1, SEK-1(KR), which unless grossly overexpressed, does not block activation of the other MAP kinase pathways. We found that expression of SEK-1(KR) in neonatal rat cardiomyocytes specifically blocked activation of the SAPKs by ET-1, but did not inhibit ET-1-induced ERK or p38 activation. Expression of SEK-1(KR) blocked all three major components of the hypertrophic response that we examined. Most importantly, SEK-1(KR) blocked ET-1-induced protein synthesis which is central to the hypertrophic response. Expression of SEK-1(KR) also completely blocked the induction of ANF mRNA expression, one of the fetal genes that undergoes renewed expression after hypertrophic stimuli. Finally, SEK$1(\mathrm{KR})$ inhibited ET-1-induced sarcomere organization, the characteristic morphological change induced in cardiomyocytes by hypertrophic stimuli. These data indicate that a functional SAPK pathway is essential for expression of the hypertrophic phenotype in response to the potent hypertrophic agent, ET-1.

p38 was only minimally and inconsistently activated by ET-1 ( $<1.5$-fold $)$ and this degree of activation was not sufficient to induce detectable activation of one of its downstream targets, MAPKAP kinase-2. In addition, SB203580 had no significant effect on ET-1-induced protein synthesis (Fig. 5 B) or on sarcomere organization (data not shown). These data, which suggest that p38 was not necessary for ET-1-induced protein synthesis or sarcomere organization, lead to conclusions different from those reached by Nemoto et al. (52). These latter investigators showed that ET-1-induced sarcomere organization and activation of a reporter construct containing the ANF promoter were blocked by SB202190, a pyridinyl imidazole related to SB203580. Although not examined in their study, it is likely that in addition to inhibiting $\mathrm{p} 38 \alpha$ and $\mathrm{p} 38 \beta$, the concentration of drug used by Nemoto et al. (10-20 $\mu \mathrm{M})$ inhibited activity of several SAPK isoforms (35). More specific inhibition of p38s is necessary in order to dissect the relative roles of these two families of kinases in the hypertrophic response $(15,35)$.

Nemoto et al. also reported that expression of a catalytically inactive mutant of SAPK enhanced MEKK-1-induced ANF promoter activity, suggesting that MEKK-1 acted via a SAPK-independent pathway. In contrast, Thorburn et al. reported that MEKK-1-induced ANF promoter activation was blocked by kinase inactive SAPK (9). These data highlight the limitations of using promoter constructs, with inherent problems of "squelching" when multiple expression plasmids are used $(53,54)$, as surrogates for biological effects.

Our experiments using gene transfer of constitutively active SEK-1, SEK-1(ED), suggest that different components of the hypertrophic response require different thresholds of activation of the SAPKs. SAPK activity was only modestly (1.5fold) increased in myocytes infected with AdSEK-1(ED). This degree of activation was sufficient to induce sarcomere organization in the absence of any hypertrophic stimulus. It was not sufficient to significantly increase overall protein synthesis but did amplify the ET-1-induced increase in protein synthesis. The difference between our findings and those of Wang et al. (14) is likely due to the greater activation of the SAPKs by MKK7 (fourfold) in their study than by SEK-1 in our study.

Our data demonstrating that the SAPKs are necessary for the hypertrophic response of cardiomyocytes must be reconciled with that of Molkentin et al. (55) which demonstrated that expression of activated calcineurin was sufficient to induce hypertrophy in transgenic mice. The calcineurin pathway consists of dephosphorylation and activation of the transcription factor, NF-AT3 (nuclear factor of activated T cells-3), by the $\mathrm{Ca}^{2+}$-calmodulin-dependent phosphatase, calcineurin. In $\mathrm{T}$ cells, full induction of many NF-AT-dependent genes requires cooperative interactions between NF-ATs and activated AP-1. Recently, crystal structure analysis confirmed that NF-AT family members form a complex with AP-1 at specific response elements contained in the promoters of many genes (56). The SAPKs regulate the activity of AP-1, which is composed of a heterodimer of c-Jun and c-Fos, by phosphorylating two serine residues in the $\mathrm{NH}_{2}$-terminal region of c-Jun, thereby increasing transcriptional activating activity of c-Jun $(57,58)$. Molkentin et al. postulated that the costimulatory 
pathway of $\mathrm{T}$ cells, which requires both calcineurin/NF-ATs and activated SAPKs/AP-1, may be operative in the hypertrophic response of cardiomyocytes (55). Our data implicating the SAPKs in the hypertrophic response strongly suggest this is the case. If so, both pathways would likely be necessary for the full expression of the hypertrophic response to physiologic stimuli, although if either is markedly constitutively activated, that may be sufficient by itself to induce hypertrophy. The current consensus is that the SAPKs and calcineurin are parallel pathways and their signals are integrated at the promoters of relevant genes by interactions of NF-ATs and AP-1. However, the calcineurin inhibitor, cyclosporin $\mathrm{A}$, has been shown recently to inhibit SAPK activation, raising the possibility that calcineurin could be upstream of the SAPKs in a linear pathway signaling hypertrophy $(59,60)$.

Analysis of promoters responsive to hypertrophic stimuli has implicated serum response factor/ternary complex factor (SRF/TCF), TEF-1, Sp1, Csx/Nkx2.5, and GATA4 in addition to $\mathrm{AP}-1(61,62$; for review see reference 63$)$, and there are undoubtedly other transcription factors which regulate the hypertrophic response in cardiomyocytes. Despite this enormous complexity downstream of the SAPKs, our data suggest that at least for ET-1, the SAPKs alone may serve as a checkpoint through which many of the signals for hypertrophy must pass. Given the wide variety of agonists which induce hypertrophy, it is unlikely that the SAPKs will be necessary for signaling the hypertrophic response to all stimuli. However, our preliminary data suggest that the SAPKs are also necessary for the angiotensin II-induced hypertrophic response (Choukroun, G., and T. Force, unpublished observations). In addition, we have found that the SAPKs are potently activated in the left ventricles of intact animals exposed to pressure overload induced by aortic banding (Force, T., unpublished observations). These data raise the possibility that the SAPKs may also be critical to the early hypertrophic response to pressure overload.

In conclusion, the SAPK pathway is necessary for the expression of the hypertrophic phenotype in response to the potent agonist, ET-1, and blockade of this pathway completely abrogates the hypertrophic response. Although the role of the SAPKs and other MAP kinases in the hypertrophic response in the intact animal is not clear, these data raise the possibility that pharmacologic inhibition of these pathways may provide novel therapeutic strategies in the treatment of hypertrophy and heart failure.

\section{Acknowledgments}

The authors would like to thank Dr. Ken Bloch for helpful discussions and probes for the Northern blots, and Dr. David Dichek for kindly providing AdLacZ.

This work was supported by US Public Health Service grants HL50361 and HL57623 (R.J. Hajjar), GM46577 (J.M. Kyriakis), DK38452, NS10828, and Merit Award DK39773 (J.V. Bonventre), HL54202, AI40970, and HL59521 (A. Rosenzweig), and DK50282 (T. Force), and by a grant from INSERM and an International Study and Research Grant of the French Lilly Institute (G. Choukroun). Dr. Force is an Established Investigator of the American Heart Association.

\section{References}

1. Force, T., C.M. Pombo, J.A. Avruch, J.V. Bonventre, and J.M. Kyriakis. 1996. Stress-activated protein kinases in cardiovascular disease. Circ. Res. 78: 947-953.
2. Kyriakis, J.M., and J. Avruch. 1996. Sounding the alarm: protein kinase cascades activated by stress and inflammation. J. Biol. Chem. 271:24313-24316.

3. Lenormand, P., C. Sardet, G. Pages, G. L'Allemain, A. Brunet, and J. Pouyssegur. 1993. Growth factors induce nuclear translocation of MAP kinases (p42 and p44) but not of their activator MAP kinase kinase (p45) in fibroblasts. J. Cell Biol. 122:1079-1088.

4. Hunter, J.J., N. Tanaka, H.A. Rockman, J. Ross, Jr., and K.R. Chien. 1995. Ventricular expression of the MLC-2v-ras fusion gene induces cardiac hypertrophy and selective diastolic dysfunction in transgenic mice. J. Biol. Chem. 270:23173-23178.

5. Thorburn, A., J. Thorburn, S.Y. Chen, S. Powers, H.E. Shubeita, J.R Feramisco, and K.R. Chien. 1993. H-Ras dependent pathways can activate morphological and genetic markers of cardiac hypertrophy. J. Biol. Chem. 268: 2244-2249.

6. Thorburn, J., M. McMahon, and A. Thorburn. 1994. Raf-1 kinase activity is necessary and sufficient for gene expression changes but not sufficient for cellular morphology changes associated with cardiac myocyte hypertrophy. J. Biol. Chem. 269:30580-30586.

7. Post, G.R., D. Goldstein, D.J. Thuerauf, C.C. Glembotski, and J.H. Brown. 1996. Dissociation of p44 and p42 mitogen-activated protein kinase activation from receptor-induced hypertrophy in neonatal rat ventricular myocytes. J. Biol. Chem. 271:8452-8457.

8. Thorburn, J., J.A. Frost, and A. Thorburn. 1994. Mitogen-activated protein kinases mediate changes in gene expression, but not cytoskeletal organization associated with cardiac muscle cell hypertrophy. J. Cell Biol. 126:15651572 .

9. Thorburn, J., S. Xu, and A. Thorburn. 1997. MAP kinase- and Rhodependent signals interact to regulate gene expression but not actin morphology in cardiac muscle cells. EMBO (Eur. Mol. Biol. Organ.) J. 16:1888-1900.

10. Ramirez, M.T., V.P. Sah, X.L. Zhao, J.J. Hunter, K.R. Chien, and J.H. Brown. 1997. The MEKK-JNK pathway is stimulated by $\alpha 1$-adrenergic receptor and Ras activation and is associated with in vitro and in vivo cardiac hypertrophy. J. Biol. Chem. 272:14057-14061.

11. Bogoyevitch, M.A., J. Gillespie-Brown, A.J. Ketterman, S.J. Fuller, R Ben-Levy, A. Ashworth, C.J. Marshall, and P.H. Sugden. 1996. Stimulation of the stress-activated mitogen-activated protein kinase subfamilies in perfused heart. Circ. Res. 79:162-173.

12. Zechner, D., D.J. Thuerauf, D.S. Hanford, P.M. McDonough, and C.C. Glembotski. 1997. A role for the p38 mitogen-activated protein kinase pathway in myocardial cell growth, sarcomeric organization, and cardiac-specific gene expression. J. Cell Biol. 139:115-127.

13. Wang, Y., S. Huang, V.P. Sah, J. Ross, J.H. Brown, J. Han, and K.R. Chien. 1998. Cardiac muscle cell hypertrophy and apoptosis induced by distinct members of the p38 mitogen-activated protein kinase family. J. Biol. Chem. 273:2161-2168.

14. Wang, Y., B. Su, V.P. Sah, J.H. Brown, J. Han, and K.R. Chien. 1998. Cardiac hypertrophy induced by mitogen-activated protein kinase kinase 7 , a specific activator for c-Jun $\mathrm{NH}_{2}$-terminal kinase in ventricular muscle cells. $J$. Biol. Chem. 273:5423-5426.

15. Cohen, P. 1997. The search for physiological substrates of mitogen- and stress-activated protein kinases in mammalian cells. Trends Cell Biol. 7:353361.

16. Sanchez, I., R.T. Hughes, B.J. Mayer, K. Yee, J.R. Woodgett, J. Avruch, J.M. Kyriakis, and L.I. Zon. 1994. Role of SAPK/ERK kinase-1 in the stressactivated pathway regulating transcription factor c-jun. Nature. 372:794-797.

17. Verheij, M., R. Bose, X. Hua Lin, B. Yao, W.D. Jarvis, S. Grant, M.J. Birrer, E. Szabo, L.I. Zon, J.M. Kyriakis, et al. 1996. Requirement for ceramide-initiated SAPK/JNK signalling in stress-induced apoptosis. Nature. 380: $75-79$.

18. Zanke, B.W., K. Boudreau, E. Rubie, E. Winnett, L.A. Tibbles, L. Zon, J. Kyriakis, F.-F. Liu, and J.R. Woodgett. 1996. The stress-activated protein kinase pathway mediates cell death following injury induced by cis-platinum, UV irradiation or heat. Curr. Biol. 6:606-613.

19. Ito, H., M. Hiroe, Y. Hirata, H. Fujisaka, S. Adachi, H. Akimoto, Y. Ohta, and F. Marumo. 1994. Endothelin ETa receptor antagonist blocks cardiac hypertrophy provoked by hemodynamic overload. Circulation. 89:2198-2203.

20. Arai, M., A. Yoguchi, T. Iso, T. Takahashi, S. Imai, K. Murata, and T. Suzuki. 1995. Endothelin-1 and its binding sites are upregulated in pressure overload cardiac hypertrophy. Am. J. Physiol. 268:H2084-H2091.

21. Sakai, S., T. Miyauchi, M. Kobayashi, K. Goto, and Y. Sugishita. 1996. Inhibition of myocardial endothelin pathway improves long-term survival in heart failure. Nature. 385:353-355.

22. Fraccarollo, D., K. Hu, P. Galuppo, P. Gaudron, and G. Ertl. 1997. Chronic endothelin receptor blockade attenuates progressive ventricular dilation and improves cardiac function in rats with myocardial infarction. Circulation. 96:3963-3973.

23. Hajjar, R.J., J.X. Kang, J.K. Gwathmey, and A. Rosenzweig. 1997. Physiological effects of adenoviral gene transfer of sarcoplasmic reticulum calcium ATPase in isolated rat myocytes. Circulation. 95:423-429.

24. Graham, F.L., and L. Prevec. 1991. Manipulation of adenoviral vectors. In Gene Transfer and Expression Protocols. E.J. Murray, editor. Humana Press, Inc., Clifton, NJ. 109-128. 
25. Pombo, C.P., J.V. Bonventre, J. Avruch, J.R. Woodgett, J.M. Kyriakis, and T. Force. 1994. The stress-activated protein kinases (SAPKs) are major c-Jun amino-terminal kinases activated by ischemia and reperfusion. J. Biol. Chem. 269:26546-26551.

26. Pombo, C., J. Kehrl, I. Sanchez, P. Katz, J. Avruch, L. Zon, J. Woodgett, T. Force, and J. Kyriakis. 1995. Activation of the SAPK pathway by the human STE20 homolog germinal centre kinase. Nature. 377:750-754.

27. Kyriakis, J.M., P. Banerjee, E. Nikolakaki, T. Dai, E.A. Rubie, M.F. Ahmad, J. Avruch, and J.R. Woodgett. 1994. The stress-activated protein kinase subfamily of c-Jun kinases. Nature. 369:156-160.

28. Pombo, C.M., J.V. Bonventre, A. Molnar, J. Kyriakis, and T. Force. 1996. Activation of a human Ste20-like kinase by oxidant stress defines a novel stress response pathway. EMBO (Eur. Mol. Biol. Organ.) J. 15:4537-4546.

29. Lowry, O.H., N.J. Rosebrough, A.L. Farr, and R.J. Randall. 1951. Protein measurement with the Folin phenol reagent. J. Biol. Chem. 193:265-275.

30. Bruder, J.T., and I. Kovesdi. 1997. Adenovirus infection stimulates the Raf/MAPK signalling pathway and induces interleukin-8 expression. J. Virol. 71:398-404.

31. Bokemeyer, D., A. Sorokin, M. Yan, N.G. Ahn, D.J. Templeton, and M.J. Dunn. 1996. Induction of mitogen-activated protein kinase phosphatase 1 by the stress-activated protein kinase signaling pathway but not by extracellular signal-regulated kinase in fibroblasts. J. Biol. Chem. 271:639-642.

32. Dickens, M., J.S. Rogers, J. Cavanagh, A. Raitano, Z. Xia, J.C. Halpern, M.E. Greenberg, C.L. Sawyers, and R.J. Davis. 1997. A cytoplasmic inhibitor of the JNK signal transduction pathway. Science. 277:693-696.

33. Alessandrini, A., H. Greulich, W. Huang, and R.L. Erikson. 1996. MEK1 phosphorylation site mutants activate Raf-1 in NIH3T3 cells. J. Biol. Chem. 271:31612-31618.

34. Goedert, M., A. Cuenda, M. Craxton, R. Jakes, and P. Cohen. 1997. Activation of the novel stress-activated protein kinase SAPK4 by cytokines and cellular stresses is mediated by SKK3 (MKK6); comparison of its substrate specificity with that of other SAP kinases. EMBO (Eur. Mol. Biol. Organ.) J. 16:3563-3571.

35. Whitmarsh, A.J., S.-H. Yang, M.-S. Su, A.D. Sharrocks, and R.J. Davis. 1997. Role of p38 and JNK mitogen-activated protein kinases in activation of ternary complex factors. Mol. Cell. Biol. 17:2360-2371.

36. Komuro, I., and Y. Yazaki. 1993. Control of cardiac gene expression by mechanical stress. Annu. Rev. Phys. 55:55-75.

37. Pennica, D., K.J. Shaw, T.A. Swanson, M.W. Moore, D.L. Shelton, K.A. Zioncheck, A. Rosenthal, T. Taga, N.F. Paoni, and W.I. Wood. 1995. Cardiotrophin-1. Biological activities and binding to the leukemia inhibitory factor receptor/gp130 complex. J. Biol. Chem. 270:10915-10922.

38. Parker, T.G., and M.D. Schneider. 1990. Peptide growth factor can provoke "fetal" contractile protein gene expression in rat cardiac myocytes. J. Clin. Invest. 85:507-514.

39. Yamazaki, T., and Y. Yazaki. 1997. Is there a major involvement of the renin-angiotensin system in cardiac hypertrophy? Circ. Res. 81:639-642.

40. Shubita, H.E., P.M. McDonough, A.N. Harris, K.U. Knowlton, C.C. Glembotski, J.H. Brown, and K.R. Chien. 1990. Endothelin induction of inositol phospholipid hydrolysis, sarcomere assembly, and cardiac gene expression in ventricular myocytes. J. Biol. Chem. 265:20555-20562.

41. Sadoshima, J., Y. Xu, H.S. Slayter, and S. Izumo. 1993. Autocrine release of angiotensin II mediates stretch-induced hypertrophy of cardiac myocytes in vitro. Cell. 75:977-984.

42. Akhter, S.A., L.M. Luttrell, H.A. Rockman, G. Iaccarino, R.J. Lefkowitz, and W.J. Koch. 1998. Targeting the receptor-Gq interface to inhibit in vivo pressure overload myocardial hypertrophy. Science. 280:574-577.

43. Dérijard, B., M. Hibi, I.H. Wu, T. Barrett, B. Su, T. Deng, M. Karin, and R.J. Davis. 1994. JNK1: a protein kinase stimulated by UV light and Ha-Ras that binds and phosphorylates the c-Jun activation domain. Cell. 76:1025-1037.

44. Han, J., J.D. Lee, L. Bibbs, and R.J. Ulevitch. 1994. A MAP kinase tar- geted by endotoxin and hyperosmolarity in mammalian cells. Science. 265:808811.

45. Sadoshima, J., and S. Izumo. 1993. Mechanical stretch rapidly activates multiple signal transduction pathways in cardiac myocytes: potential involvement of an autocrine/paracrine mechanism. EMBO (Eur. Mol. Biol. Organ.) J. 12:1681-1692.

46. Bogoyevitch, M.A., A.J. Ketterman, and P.H. Sugden. 1995. Cellular stresses differentially activate c-Jun $\mathrm{N}$-terminal protein kinases and extracellular signal-regulated protein kinases in cultured ventricular myocytes. J. Biol. Chem. 270:29710-29717.

47. Komuro, I., S. Kudo, T. Yamazaki, Y. Zou, I. Shiojima, and Y. Yazaki. 1996. Mechanical stretch activates the stress-activated protein kinases in cardiac myocytes. FASEB (Fed. Am. Soc. Exp. Biol.) J. 10:631-636.

48. Kudoh, S., I. Komuro, T. Mizuno, T. Yamazaki, Y. Zou, I. Shiojima, N. Takekoshi, and Y. Yazaki. 1997. Angiotensin II stimulates c-Jun $\mathrm{NH}_{2}$-terminal kinase in cultured cardiac myocytes of neonatal rats. Circ. Res. 80:139-146.

49. Heasley, L.E., B. Storey, G. Fanger, L. Butterfield, J. Zamarripa, D Blumberg, and R.A. Maue. 1996. GTPase-deficient $\mathrm{G} \alpha 16$ and $\mathrm{G} \alpha \mathrm{q}$ induce PC12 cell differentiation and persistent activation of c-Jun $\mathrm{NH}_{2}$-terminal kinases. Mol. Cell. Biol. 16:648-656.

50. Thorburn, J., M. Carlson, S.J. Mansour, K.R. Chien, N.G. Ahn, and A. Thorburn. 1995. Inhibition of a signaling pathway in cardiac muscle cells by active mitogen activated protein kinase kinase. Mol. Biol. Cell. 6:1479-1490.

51. Marshall, C. 1995. Specificity of receptor tyrosine kinase signalling: transient versus sustained extracellular signal-regulated kinase activation. Cell. 80:179-185.

52. Nemoto, S., S. Zelin, and A. Lin. 1998. Opposing effects of Jun kinase and p38 mitogen-activated protein kinases on cardiomyocyte hypertrophy. Mol. Cell. Biol. 18:3518-3526.

53. Natesan, S., V.M. Rivera, E. Molinari, and M. Gilman. 1997. Transcriptional squelching re-examined. Nature. 390:349-350.

54. Gill, G., and M. Ptashne. 1988. Negative effect of the transcriptional activator GAL4. Nature. 334:721-724.

55. Molkentin, J.D., J.R. Lu, C.L. Antos, B. Markham, J. Richardson, J. Robbins, S.R. Grant, and E.N. Olson. 1998. A calcineurin-dependent transcriptional pathway for cardiac hypertrophy. Cell. 93:215-228.

56. Chen, L., J.N.M. Glover, P.G. Hogan, A. Rao, and S.C. Harrison. 1998. Structure of the DNA-binding domains from NFAT, Fos, and Jun bound specifically to DNA. Nature. 392:42-48.

57. Pulverer, B., J.M. Kyriakis, J. Avruch, E. Nikolakaki, and J.R. Woodgett. 1991. Phosphorylation of c-jun mediated by MAP kinases. Nature. 353:670-674.

58. Karin, M. 1995. The regulation of AP-1 activity by mitogen-activated protein kinases. J. Biol. Chem. 270:16483-16486.

59. Matsuda, S., T. Moriguchi, S. Koyasu, and E. Nishida. 1998. T lymphocyte activation signals for interleukin-2 production involve activation of MKK6p38 and MKK7-SAPK/JNK signaling pathways sensitive to cyclosporin A. $J$. Biol. Chem. 273:12378-12382.

60. Su, B. E. Jacinto, M. Hibi, T. Kallunki, M. Karin, and Y. Ben-Neriah. 1994. JNK is involved in signal integration during costimulation of T lymphocytes. Cell. 77:727-736.

61. Lee, Y., T. Shioi, H. Kasahara, S.M. Jobe, R.J. Wiese, B.E. Markham, and S. Izumo. 1998. The cardiac tissue-restricted homeobox protein Csx/Nkx2.5 physically associates with the zinc finger protein GATA4 and cooperatively activates atrial natriuretic factor gene expression. Mol. Cell. Biol. 18:3120-3129.

62. Durocher, D., C.Y. Chen, R.J. Ardati, R.J. Schwartz, and M. Nemer. 1996. The atrial natriuretic factor promoter is a downstream target for $\mathrm{Nkx}-2.5$ in the myocardium. Mol. Cell. Biol. 16:4648-4655.

63. Molkentin, J.D., and E.N. Olson. 1997. GATA4: a novel transcriptional regulator of cardiac hypertrophy? Circulation. 96:3833-3835. 